\title{
Health-care assistants, aspiration, frustration and job satisfaction in the workplace
}

\section{Ian Clark}

\begin{abstract}
This paper focuses on health-care assistants as individuals and a sectional group in terms of how they experience the NHS modernisation and skill mix agenda. Empirical material focuses on aspiration, frustration and job satisfaction. Findings report highly sectional work groups which promote populist coping strategies.
\end{abstract}

\section{INTRODUCTION}

Over the past thirty-five years a reform cum modernisation agenda in the delivery and provision of health care in the UK has witnessed concerted and sustained attempts by Conservative and Labour governments to re-structure professionalised bureaucracy models which have sustained clinician dominance in the National Health Service since its creation in 1948. Thatcherite reforms in the 1980s focused on what is now termed new public management which aimed to dilute clinician dominance and introduce a strong performance management culture. After $1997 \mathrm{New}$ Labour tied higher spending on the NHS to an explicit modernisation and reform agenda which tied improved quality in care provision with improved cost effectiveness. The combined aim of these reform strategies was the creation of a division of labour wherein health-care professionals became subject to control by hospital managers. Within new public management managers increasingly focus on the rhetoric of patients as customers and service provision as a quality experience (see Bolton, 2004, Ferlie et al., 2013, and Hartley and Skelcher, 2008). One innovation which has continued un-interrupted through the Thatcher, Major, Blair, Brown and Cameron governments is the development, extension and further development of Health Care Assistants (HCAs) in NHS hospitals.

A considerable literature has grown to follow the development, role, status and controversies which surround the HCA role. However, much of the literature centres on the relationship between registered nurses and HCAs and the relationship of both groups to government policy in the modernisation agenda. This paper contributes to this debate by focusing specifically on HCAs as individuals and as a sectional group in terms of how they experience the macro modernisation agenda and the micro

$\square$ Ian Clark is a Professor in the School of Management, University of Leicester. Correspondence should be addressed to Professor Ian Clark, Centre for Sustainable Work and Employment Futures, The University of Leicester, Leicester LE1 7RH; email: IC70@le.ac.uk. The Centre is funded by the Medical Research Council and the Economic and Social Research Council. 
impact of this in their relationship with registered nurses (RNs) in a large teaching and university hospital, (TUH). The paper divides into four parts. Part one reviews the literature on the emergence and use of HCAs. Part two outlines the research design and details how the empirical evidence was constructed to inform a critical case approach. Part three reports on narrative findings from empirical work. Part four provides a discussion of the narrative findings to identify the contribution of this study in respect of the research questions outlined in part one and is followed by a conclusion.

\section{HEALTH-CARE ASSISTANTS, SKILL MIX AND MODERNISATION}

Recruited from unqualified support staff the term HCA describes staff who are working toward NVQ level two or three in health care. HCAs undertake nursing duties and direct patient care for example, bathing, monitoring and observing patients and talking to patients and their relatives, Thornley (2000). In the latter roles HCAs may be able to form closer relations with patients and relatives than registered nurses who since the diffusion of the HCA role are increasingly concerned with the management of medication, paperwork and scheduling, (Bosley and Dale, 2008: 119, Hancock and Campbell, 2006). Training for HCAs is neither formalised in a standard manner nor is it subject to statutory regulation rather HCAs demonstrate evidence of competence and associated underpinning knowledge on a portfolio basis. Increasingly then it is possible to view the occupational structure which stratifies registered nurses, ward managers and HCAs as one which divides defined occupations. That is, a graduate route for registered nurses and ward managers and a non-graduate vocational route into health care for HCAs. The demarcation between the two groups centres on efforts towards occupational closure by registered nurses, the associated creation of a job category subordinate to registered nurses and a related division of labour between the two groups, but one which is defined by registered nurses.

Daykin and Clarke (2000) provide a qualitative study which examines modernisation and skill mix as fordist strategies sponsored by the state and formulated by hospital managers that aim to de-skill and routinise elements of nursing work. As an internal division of labour the modernisation agenda sees qualified graduate nurses move away from the delivery of care towards administrative, technical and supervisory roles. Aspects of nursing work became routinised, that is standardised and de-skilled and in effect delegated to HCAs. Daykin and Clarke (2000) found that whilst registered nurses held ambivalent attitudes towards modernisation HCAs saw it as an opportunity to develop knowledge and skills and increase their workplace independence and level of job satisfaction. Moreover, the attitudes of both groups enabled hospital managers to further diffuse modernisation as an internal division of labour to reduce reliance on agency and bank nurses in favour of HCAs and therefore contain costs. Spilsbury and Meyer (2004) provide case study findings on the changing role of registered nurses and evaluate the impact of this on the role of HCAs in the delivery of nursing care. The study finds that whilst HCAs complement, supplement, replace or substitute for registered nurses HCA work is confined to direct patient care whereas registered nurses concentrate more on housekeeping and clerical duties. This strategy often has the effect of ignoring HCA 'local knowledge' of patients and seeks to demarcate and restrict the work of HCAs to reflect explicit and implicit efforts towards occupational closure by registered nurses. Keeney et al. (2005) found that 
HCA work was confined to non-nursing activity such as bed making, 'portering' and clerical duties. Like Wakefield (2002) these authors conclude that registered nurses are satisfied with the support roles undertaken by HCAs but that in contrast to this HCAs regard registered nurses as uncaring towards patients, inefficient in what they do and possessive of few clerical skills. Bach et al. (2005) suggest that a key aspect of the modernisation agenda is the manner in which performance management systems actively embrace human resource management metrics, for example, absence, staff turnover and the quality of working life as a series of bureaucratic controls in the workplace. More specifically Hyde et al. (2005: 704) examines the manner in which role redesign in the health service results in HCAs substituting for registered nurses. This theme is also highlighted by Nancarrow and Borthwick (2005) who report that unskilled HCAs now undertake tasks previously performed by registered nurses. This development operates within UK health policy which since 2000 has emphasised flexibility in the context of labour shortages and the performance management requirements of enhanced patient care, (Bosley and Dale, 2008, Department of Health, 2000). The authors report that as registered nurses specialise on tasks beyond direct care this component of nursing does indeed become de-skilled and routinised to focus a legitimate subordinate group below registered nurses. The focus on HCAs as a subordinate group is for some essential to maintain occupational closure for registered nurses. Thornley (2007) examines skill mix and modernisation in the context of these occupational closure strategies. Within this flexible cross boundary working between nurses and HCAs is presented as a self-proclaimed policy achievement. However, whilst cross boundary flexible working prevails HCAs perceive themselves as substitutes for registered nurses and initially accepted this degradation on the basis of promised progression opportunity and appropriate training opportunities to secure progression. Moreover, Thornley argues that the aim of de-skilling and routinisation was achieved in improved cost effectiveness which cheapened labour in the health service. Saks and Allsop (2007) present research commissioned by the department of health which confirms Thornley's conclusion to suggest that as a group HCAs are largely female, low paid, work part-time, hold varying levels of education and training but are on the whole low skill workers. None the less HCAs are gradually replacing nursing auxiliary grades and do in some circumstances substitute for registered nurses in areas previously beyond the remit of nursing auxiliaries.

The conclusions presented by Thornley (2007) and Saks and Allsop (2007) are further confirmed by Bach et al. (2007). Therein the authors argue that HCAs operate in a largely substitute supportive capacity defined by the wider goals of public service delivery in particular cross party fiscal prudence and efforts to retain recruited labour in the context of tighter labour cost budgets. However, as registered nurses and HCAs play out ill-defined blended but co-professional roles potentially contradictory outcomes for both groups are likely to develop. Bach et al. (2008) go on to further specify these contradictions in terms of the relationship between the two job roles. Specifically, because differing models of nursing operate within and between national health service trusts they create different boundaries between registered nurse and HCA roles in different hospitals. In turn this is likely to make strategies for authoritative job re-design and consistent approaches to HR policy difficult to achieve. Bach et al. (2012) provide further theoretically informed empirical detail on the manner in which HCAs replace auxiliary nurses. However, they find that because the work of HCAs is poorly defined occupational boundaries and therefore efforts to secure occupational closure by registered nurses in particular become blurred. Both registered nurses and 
HCAs seek to identify their specific contribution to health care and define its boundary. However, registered nurses define HCAs as helpers viewing the educational credentials they possess as marginal differentiating themselves from HCAs in terms of technical competence and a distancing from de-skilled delegated 'dirty work'. In contrast to this, HCAs view themselves as providing hands on care and emotional support for patients stressing the similarity of their contribution to that of registered nurses. The study concludes that blended outcomes are contingent on local contexts and that this situation prevails because of the lack of a clearly defined workplace role for HCAs which in turn impedes more strategic efforts at job re-design across the health service. This conclusion is developed further in Kessler et al. (2013) where it is reported that changes in the role of registered nurses has created a space for HCAs. However, the absence of a clearly defined job role for HCAs in the skill-mix modernisation agenda creates the potential for five overlapping HCA typologies ranging through 'bedside technician', ancillary, citizen, all-rounder to expert. More significantly the study found that HCAs who occupied citizen and all-rounder roles possessed high levels of personal confidence in their role and abilities whereas HCAs who occupy other typologies demonstrate experience and capability but prefer not to go beyond a self-defined comfort zone. Hence the key issue in defining the role of a HCA is the human agency of the individual and the manner in which this interacts with organisational structures. For example, Long et al. (2014) found that 50 per cent of HCAs declined to get involved in clinical supervision preferring ancillary duties instead. A more abstract overarching study suggests that since the 1990s HCAs have come to experience their role not as an end-game or matter of fact but as part of on-going attempts to break-up the professional bureaucracy model which has dominated in the health service since its creation, (Ferlie et al., 2013: 1-5, chap. 2).

This review of the literature provides three broad findings each of which inform three further research questions. Firstly, that HCAs are substitutes for registered nurses as the skill-mix and modernisation strategies routinise and de-skill aspects of nursing care to unqualified, unregistered and therefore cheaper labour. Therefore the first research question centres on how do HCAs experience skill mix and modernisation strategies as a form of job re-design? The second finding from the literature suggests that HR policies to re-design jobs are necessary to secure the cheapening of labour yet the absence of clearly defined job roles for HCAs and registered nurses frustrates this aim. Moreover, this absence creates localised boundary tensions between the two work groups that have job satisfaction implications for HCAs in particular. It follows from this that a second research question centres on how job re-design reflects a locally restricted approach to HCAs at TUH? A 'locally restrictive' approach to HCAs suggests that registered nurses seek to protect their holistic patient centred role by delegating nursing and direct patient care tasks to HCAs as unstructured subordinate individual tasks. The third finding from the literature suggests that HCAs are often subject to detailed but abstract research, that is, they are evaluated in terms of policy measures and the effects of these on registered nurses not necessarily themselves as an integral group. Hence the third research question centres on how HCAs experience the locally restricted approach to HCA management as workplace aspiration, frustration and job satisfaction? In other words the manner in which the HCA labour process is and remains a contested terrain where some aspects of new public management are accommodated whereas others are resisted.

Many contributions to the literature on skill mix and modernisation strategies in the National Health Service either highlight or mention the impact of these strategies 
on HCAs vicariously or in the context of the impact they have had on registered nurses in terms of occupational closure. This paper adds to the literature by providing new empirical data on how HCAs experience de-skilling and routinisation in a localised setting. How the relationship between HCAs and registered nurses creates boundary tensions between the two groups and lastly how these tensions have an impact on job satisfaction and associated coping strategies in a highly sectional workgroup such as HCAs.

\section{RESEARCH DESIGN AND METHODS}

Qualitative research seeks to establish and explain causal relationships and in this research causal relationships are detailed, documented and cross referenced in four ways. First through interviews with HCAs, second by observations of HCAs at work, third by reference to hospital policy documents on the role of HCAs and fourth by reference to any appropriate HR policy documents on the HCA role. The research examines the aspirations and frustrations of HCAs at work at TUH measuring both of these qualitatively in terms of job satisfaction. TUH is one of the largest teaching and university affiliated hospital trusts in the midlands and employees nearly 8000 people over two large sites. TUH was one of the first hospitals to secure NHS foundation trust status in 2004. Currently TUH has 1200 beds and treats around 90,000 in-patients a year of which approximately 1300 died at the hospital in 2010. In 2013 TUH was one of thirteen hospitals named by Dr. Foster Intelligence [HSJ (Health Service Journal), 2013] as having greater than acceptable mortality rates but the hospital self-reports no MRSA cases for over a year, (anonymised hospital website). TUH has an in-house call bank for HCAs and in addition to this often calls in regular external agency staff. In house bank HCAs either work very flexibly at short notice as a form of zero hours spot contracting or permanent HCAs do bank work as a form of over-time.

By using mixed methods the research combines primary and secondary research where a pilot study supported by examination of recruitment and retention material for HCAs revealed two findings. The absence rate for HCAs was significantly higher than the average absence rate for all none medical hospital staff and high absence rates did not convert into quit rates. The pilot study findings focused on an evident disconnect between absence rates and quit rates and the apparent inability of HR to arrest the persistently high absence rate. For this bigger project the main research method was interviews conducted by a team of interviewers in the hospital. Sixty semi-structured interviews were conducted with HCAs supported by a structured questionnaire and three further interviews with the head of delivery at the hospital. Interviews averaged sixty minutes in length but some were as long as ninety minutes. At TUH half of all HCAs are positioned on band $3(£ 16,110-£ 19,077)$ of the pay scale and the head of delivery confirmed that no HCAs were remunerated on band four. In comparison the minimum starting salary for registered nurses in 2012-2013 was $£ 21,176$ placing the minimum starting salary at the bottom of band 5 [RCN (Royal College of Nursing), 2012]. Therefore the minimum starting salary for a registered nurse is $£ 2099$ higher than the maximum HCA salary, excluding overtime payments.

Interview transcripts were coded against the three research questions with the findings checked against documents provided by the delivery unit and human resources. These findings were further informed by material gathered in the structured questionnaire. The pilot study was conducted in April 2012 and the main fieldwork 
interviews were undertaken in two batches of thirty over three weeks in July 2012. In January 2013 initial findings were presented in separate workshops to HCAs, the delivery unit and the HR function. Workshop results were then subject to focus group evaluation by each constituency. Whilst the main research method is qualitative, and bearing in mind that this is a single site study, in some instances these findings are also presented numerically and quantitatively in order to express the significance of particular issues to the HCA constituency at TUH. In summary the research presents a theoretically informed single site case study which has collected data through interviews, workplace observation, documents and other material from the field site. The data was analysed through thematic content analysis which coded the material for evidence of constructs and significant relationships on absence, quit rates, aspiration and job satisfaction.

\section{EMPIRICAL FINDINGS ON HCA ASPIRATION, FRUSTRATION AND JOB SATISFACTION}

\subsection{How do HCAs experience skill mix and modernisation strategies?}

All respondents both in interviews and in questionnaire transcripts saw themselves as lower cost workplace substitutes for registered nurses and accepted their roles in the performance of work tasks described as routinised work. These tasks covered 'dirty work', trolley work, moving and rotation of patients, help with eating and drinking, washing and bed sore control and some wound dressing work. The vast majority of HCAs interviewed did not however accept that these tasks were de-skilled because HCAs performed them rather than registered nurses. Many interviewees argued that whilst these tasks were subject to grade degradation this was not the same as de-skilling because the tasks cited above and others such as catheter maintenance could not be de-skilled in terms of job content. Moreover, forty interviewees argued that this was an inappropriate term to use because many registered nurses, that is, those theoretically more skilled than HCAs, could not actually undertake these tasks and that this was part of the problem in how they experienced skill mix and modernisation. Twenty of these interviewees stated that they experienced both skill mix and modernisation as labour shortages with a further fifteen interviewees stating that they experienced labour shortages as stress, for example, bullying and having to run to get things done. The regular response reported across the sixty interviews was: 'nurses don't help'.

Variations on this statement were reported in forty-five of the sixty interviews. So HCAs as individuals and as a work group experience modernisation and skill-mix strategies at TUH as staff shortages, related workplace stress and associated pressures from managers and registered nurses. The experiences of HCAs as a work group demonstrate work intensification at TUH resulting from faster patient turnover and greater use of day surgery year on year without a corresponding increase in registered nurse numbers, (see also Bolton, 2004: 324). These developments result in the delegation of more direct patient care work to HCAs as a subordinate group both in absolute numbers and more intensive repetition of tasks, for example, patient delivery to theatre or procedure and waiting areas.

This is a big hospital and you spend a lot of time walking around pushing patients, this gets to be heavy work. Sometimes schedules are so tight you are in effect running pushing a patient or running to get a patient [HCA, 41]. 
If you don't get them where they need to be on time slots are missed and they don't get seen or have to wait a long time so you feel you have to get them there but you might not [It's not always like this but can be] [HCA, 23].

In addition to work intensification HCAs experienced further negative aspects of skill mix and modernisation in a variety of ways. First, staff shortages both create stress for those at work and are an indicator of stress as HCAs react to work with coping strategies such as calling in sick when they are not ill. Alternatively, genuine illness may result from overwork often in the form of back pain resulting from attempting to perform tasks which really require two HCAs. Second, absent colleagues cause stress for those who are at work. Fifty four interviewees stated that absence causes regular delays in outpatients and patient care causing TUH to continually fall back on in-house bank staff or external agency staff. All sixty interviewees stated that delays in patient treatment in outpatients and on wards could easily be solved if managers and nurses stepped in to help out. Thirty interviewees stated and provided corroborative information to support their claims that they had experienced managers and nurses declining to help them when HCA absence was causing delays in patient treatment.

If I had told you this before north staffs you would not have believed it. In fact you would have refused to do so [HCA, 35].

The interviewee recounted examples of nurses refusing to help several patients in distress 'because it was dirty work' and instead issuing an instruction to a HCA to do it and leave something else. A third way in which HCAs experienced modernisation and skill mix was 'as a job'. This response was given by 40 interviewees and became manifest in two sub-responses one which highlighted limited pay and reward opportunities and a second related response which suggested that promised learning and development opportunities were either limited or non-existent. Fifty of the interviewees suggested that the relentlessness of the three ways in which HCAs experience modernisation and skill mix gradually encouraged them to see their role as a job. In contrast to this all interviewees stated that they had entered the job to help people and get on the nursing career ladder. However, HCAs saw a boundary between themselves and registered nurses strictly enforced even in emergency circumstances such as serious road traffic accidents when there were never enough HCAs.

To summarise modernisation and skill mix at TUH are experienced by HCAs as alienation and degradation in the form of a sticky floor where they are stuck due to limited opportunities and career development. Alienation was manifest as having to act like registered nurses, that is, reducing or curtailing bedside relationships with patients and relatives. This was not necessarily the case because HCAs wanted to do so but felt compelled to do so in order to get the job done. Alienation like this had a double effect; it demonstrated movement from this is a 'caring job' to 'this is a job' but whilst some HCAs felt that they were compelled to act like registered nurses they had 'no chance' [HCA 5] of becoming one and some HCAs felt the job was becoming more degrading because of its dead-end status, (see also Wise, 2007: 478). These frustrations encouraged HCAs to cope by dis-engaging from caring at work - the 'just a job' response as opposed to 'this is a caring job'. This finding began to help explain the very high absence rates for HCAs. For HCAs with more than a year in the job absence came out at 18 days and for HCAs with less than a year in the job at 3.3 days. (These figures calculated from the sixty interviews were almost identical to those later provided by the delivery unit). More interestingly for the second and third research 
questions twenty HCAs had absence rates longer than the CIPD definition of long term absence - twenty days - but only ten of this group had a defined long-term cause for absence with the other ten citing two or more reasons for short-term absence all of which (other than family related absences) related to injury at work. In contrast to this thirty four HCAs had experienced short-term absence which is defined by the CIPD as less than seven days, [CIPD (Chartered Institute of Personnel and Development), 2012]. All of these were categorised as illness contracted at work. The top five citations were viral infections, flu, diarrhoea and vomiting, conjunctivitis and skin disorders and back pain. For absences other than back pain twenty of the thirty four HCAs citing short-term absence stated that they can catch these ailments as a result of staff shortages as germs and viruses are 'left hanging around' and not cleaned up promptly.

\subsection{Modernisation and skill mix: a locally defined approach?}

In terms of the stock of literature HCAs at TUH experience modernisation and skill mix as a highly localised boundary issue where delays to patient care and use of bank and agency staff to solve delays appear as an accepted workplace response. A focus on these issues returned attention to the issue of managers and nurses not stepping in to alleviate HCA staff shortages. In the findings from both interviews and questionnaires it proved difficult to find responses that cited or referred to specific TUH policies which defined the boundary between the work of registered nurses and work which was delegated to HCAs. From this and evaluation of TUH policy documents it appears safe to conclude that the job roles of the two groups had not been formally defined or re-designed. The responses did however regularly allege that 'They (nurses) just don't do that', in references to activities which registered nurses won't undertake. Many HCAs argued that registered nurses now effectively saw themselves as 'schedulers' and managers to whom it didn't matter if patient care was delayed because it created another 'none nursing' nursing job for them to do which could be massaged and masked in any performance management figures.

They (registered nurses) don't really care about delays and absences it gives them the opportunity to manage something else. They? (prompted) nurses and the delivery people are like the railways they can always find a good defendable reason to explain why something hasn't been done. The hospital is primarily concerned with A \& E targets not what goes on with nurses and HCAs [HCA 10].

The interview team reported the views of HCAs but also attempted to get interviewees to substantiate their claims. Whilst this was necessary it was problematic and risky. A majority of the sixty HCAs demonstrated good motivation (low absence rates and a commitment to patients as people) but others were alienated and secondly many did not feel that explaining absence or diagnosing why things went wrong was part of their job. In some ways these responses are reminiscent of highly sectional work groups and their responses to relations with managers and so-called 'managerial problems', (see Batstone et al., 1977; 1978). In this case it appears HCAs manage their own populist sectional interests by recourse to absence in efforts to manage the 'frontier of control' in the workplace. Moreover, the responses of interviewees were highly sectional but un-reconstructed, that is they were not expressed in either a traditional rank and file militancy approach or an institutionalised job regulation approach structured via collective bargaining. This was the case even though forty two HCAs were union members and many saw recourse to absence as acceptable action in addition to whatever the union might do for them. HCAs were quite happy 
to provide documented material on these claims including dates of incidents and the names of individuals concerned and sometimes those of individual patients and or wards. These offers and the frequency of them suggested to the research team that this claims were not fanciful. Indeed several HCAs stated that they were not telling us anything that they had not told to the union or their managers 'and anyone else who will listen'.

\subsection{HCA job satisfaction, aspiration and frustration}

Interviews and questionnaires measured job satisfaction across a range of categories and factors; individual HCAs absence rates, propensity to quit, how HCAs rated job satisfaction and how job satisfaction had moved over the past couple of years. Overall, of the sixty interviewees forty five stated that their job satisfaction was satisfactory or better, nine stated that job satisfaction was less than satisfactory but not unsatisfactory with six HCAs stating that job satisfaction was unsatisfactory. This result was repeated in questionnaire responses along a five point likert scale. These results were then cross referenced with the questionnaire findings from the twenty HCAs who had long-term absence where thirteen stated that their job satisfaction was satisfactory or better. For each of the fifteen HCAs who experienced less than satisfactory or low job satisfaction none demonstrated any propensity to quit. The coping strategies used by this sub-group to manage their job satisfaction included being absent from the workplace, whereas longer serving HCAs reminding themselves that they had too many years in to consider quitting. That is, the benefits of a comparatively good pension scheme etc. could not be given up. In contrast to this less long-serving HCAs cited current economic conditions:

this job is not great bit its pay and working terms are in the current economic climate pretty good [HCA 14].

Economic fear kept some of this sub-group in the job. Moving to aspiration and frustration at work fifteen interviewees stated that job satisfaction at work could be improved by the presence of career incentives such as a career pathway and potential pay band improvement to band four. Those who cited this response were distributed evenly across the range and were not confined to HCAs who cited less than satisfactory or unsatisfactory job satisfaction. Workplace frustration was evident both individually and collectively as a sectional work group. In response to questions that sought to explain the absence of individual HCAs 32 interviewees stated that staff shortages and related workload stress resulting from staff shortages was the reason for their individual absence from work. In contrast to this only two interviewees stated that lack of career progression prompted their absence. As a sectional group workplace frustration was experienced by HCAs in terms of how absence affected job performance. Fifty four interviewees stated that absence amongst their work group caused delays in outpatient and patient care on wards and cited specific examples of this effect. More specifically, fifteen interviewees stated that absence amongst their work group was a 'double whammy' because in response to absence bank and agency staff had to be brought in and this created more work for HCAs as some agency and bank staff did not know their way around TUH etc. Thirty interviewees stated that delays in patient care and cancellations could be avoided if managers and nurses stepped in to help out. 


\section{DISCUSSION AND CONCLUSION}

The research questions addressed in this study focus on how HCAs at TUH experience skill-mix strategies, how the substitution of HCAs for registered nurses enables a highly localised approach to degradation and de-skilling of HCA roles and how these effects are manifest in terms of HCA aspiration and frustration? What this study adds to the existing stock of literature is a workplace analysis of why HCAs assume disengaged or aspirational attitudes and roles which stimulate unsophisticated and highly sectional reactions in the workplace.

On the first research question HCAs experience modernisation and skill mix strategies as workplace degradation and de-skilling but informally. As Saks and Allsop (2007) and Thornley (2007) demonstrate HCAs are less skilled than registered nurses and therefore cheaper but have a role wider than that which nursing auxiliaries previously occupied. Therein registered nurses delegate tasks to HCAs and use them as a lower cost substitute. At TUH this degrades HCAs precisely because at state level these strategies lack definition and structure to become enforced in local flexibility defined by registered nurses and ward managers.

More specifically on the second research question, the locally defined approach to HCA management exclude HCAs from management discussion leaving them virtually ignored as a group of workers. Therefore 'local knowledge' held by HCAs on patients was not utilised at all. The localised approach could be described as 'distant and delegated' where registered nurses are distant from HCAs but consistently delegate to them as a group. TUH HCAs were initially accepting of degradation but found the absence of promised progression and training as a growing frustration. HCAs feel overworked and underpaid where low pay and more particularly the enforced pay gap in the occupational structure between nurses and HCAs reinforces the characteristics of the sector and grades of worker within it.

The substitute role is non-specific in the sense that it can emphasise whatever registered nurses and to a lesser (un-reported) extent what HCAs suggest it represents. The absence of a clearly defined role for HCAs frustrates HR policy and makes job re-design problematic. These effects can impose on many issues much wider than the specifics of this study for example, equal pay claims and grading disputes. At TUH the absence of definition results in HCAs experiencing modernisation and skill mix strategies as only potentially innovative and encouraging. In contrast to this the absence of a clearly defined nationally implemented job role descriptor for HCAs renders skill-mix strategies frustrating and isolating as promised training and development opportunities to support career progression fail to arrive. In turn this absence appears to reinforce existing occupational boundaries albeit in a blurred manner. This pushes issues of pay grading, promotion and training and development back to local negotiation. As this study demonstrates this can be problematic if the locally defined approach to the boundary between registered nurses and HCAs is both highly restrictive, that is, focused on professional closure by nurses and highly delegated in the dispersal of unwanted routinised tasks. If the aim of modernisation was to dilute, reform and re-structure sustained clinician dominance in the National Health Service it has done so at TUH in a flawed manner which has encouraged HCAs to become a highly sectional if unstructured weakly unionate work group. Hence at TUH HCAs are highly sectional in the manner in which they are alienated from registered nurses and the modernisation agenda. On the receiving end of modernisation, HCAs feel no sectoral solidarity with registered nurses in respect of de-skilling and routinisation 
which affects both work groups. While nurses seek to secure their professional status at expense of HCAs HCAs are in some areas of so-called de-skilled work, technically much more competent than registered nurses. The disconnect may be opportunistic because at TUH it enables and sustains a variety of local practices. Local practices and degrees of degradation may be similar or different in other workplaces across the city where TUH is located, that is the burden of implementing modernisation falls on unguided, if instrumental local managers.

On the third research question of aspiration, frustration and job satisfaction there is a disjuncture between what HCAs feel and say about themselves as individuals and what they say as a group particularly about job satisfaction and aspiration. As a group HCAs have 60 per cent + union density but never the less they are not necessarily very unionate, that is they do not act collectively or necessarily in accordance with strongly held union principles. However, they do appear highly sectional and self-interested where strategic use of absence is championed by many HCAs, and more importantly its apparent tolerance by TUH substitutes for collective industrial action. On job satisfaction the majority of HCAs interviewed in this study report satisfactory or better job satisfaction which in some cases could be further improved if there were better pathway options and career pathways. The absence of hygiene factors related to status and status aspiration were on the whole not significant enough to reduce individual satisfaction scores across the range of satisfaction levels. Nineteen interviewees stated that they were not interested in career progression whereas twenty four did, that is, only five per cent more of the whole interview group.

Therefore this situation prevails because official workplace representatives appear unable to coordinate sectional sub-groups or even individual HCAs. That is, Batstone's typology predicts shop stewards to be sophisticated in their relations with managers whereas at TUH if sophistication exists it is superseded by more populist tactics at the workplace. These mimic aspects of collective workplace behaviour but most HCAs even if a union member felt that use of individual absence was more appropriate than unionate collective action. Twenty one of the sixty interviewees stated that for them job satisfaction was satisfactory or better even in the face of lack of promotion opportunities and a defined career pathway whereas forty HCAs did express aspirational career and promotion aims in the workplace. Thus, HCAs may use absence as a coping mechanism for workplace stress and workload issues which result from the absence of colleagues, however, at the moment absence does not convert into quits and neither does workload and stress reduce good levels of job satisfaction. What this does demonstrate is the emergence of an aspirational group of HCAs and a group who are alienated from the job seeing it as 'just a job'. Whilst as a group HCAs appear highly sectional and defensive the strategies they employ to cope with the modernisation agenda reflect the presence of the two distinct types of HCA. On the one hand those who view their role as just a job not a caring job and those who may or may not. The latter emphasise caring and are highly aspirational but on an individual basis in the ambition of becoming a registered nurse and appear less supportive of collective action. Both sub-groups express highly populist views and have little commitment to trade union principles.

In the focus group for HCAs the majority of those who described themselves as aspirational fitted into the citizen and all-rounder typologies identified by Kessler et al. (2013). Most of the HCAs who fitted with these two typologies held relatively short periods of job tenure. It remains for further research to examine the extent to which 
the absence of promotion opportunities encourages aspirational HCAs to modify their aspirations and become part of the more established detached longer served sub-group; alternatively they may quit.

HCAs view job satisfaction at all levels and related absence as a management problem not a job regulation related issue. These views represent un-constructed industrial relations where management get what they deserve with HR initiatives and the HR function having only a marginal effect on the attitudes of HCAs in either aspirational or job mode. In-effect ward managers become employers where resistance to management control appears more individually focused rather than collectively focused. In summary at the level of the state the reform agenda for the National Health Service aimed to dismantle clinical dominance through a skill-mix and modernisation agenda one component of which focused on the relationship between registered nurses and HCAs. However, at state level and management level too the strategy is only partially fulfilled due to a failure of strategic management in respect of job re-design focused on the boundary between registered nurses and HCAs. As the established literature and this study demonstrate this failure leads to highly localised approaches to HCAs which whilst effective at the headline level in terms of labour cheapening still lack formalised approaches to job-redesign and work allocation. In this study one effect of this was to galvanise HCAs as a highly sectional if populist workgroup who exercise day to day resistance to workload pressures and routinisation through the use of absence to maintain levels of job satisfaction. Further still this study demonstrates that HCAs have an internal dynamic wherein some are aspirational and others dis-engage from the caring side of the job.

\section{Acknowledgements}

Thanks to Peter Foss and Viashali Saple for research support. Thanks to Jane Whitmarsh for office management and Jacqui Ward for financial management of projects.

\section{References}

Bach, S., I. Kessler and P. Heron (2007), 'The Consequences of Assistant Roles in the Public Services: Degradation or Empowerment?', Human Relations, 60, 9, 1267-1292.

Bach, S., I. Kessler and P. Heron (2008), 'Role Re-design in a Modernised NHS: The Case of Health Care Assistants', Human Resource Management, 18, 2, 171-187.

Bach, S., I. Kessler and P. Heron (2012), 'Nursing a Grievance? The Role of healthcare Assistants in a Modernized National Health Service', Gender, Work \& Organization, 19, 2, 205-224.

Bach, S., I. Kessler and G. White (2005), 'Introduction: Employment Relations and Public Services under Labour', Personnel Review, 34, 6, 629-633.

Batstone, E., I. Boraston and S. Frenkel (1977), Shop Stewards in Action (Oxford, Blackwell).

Batstone, E., I. Boraston and S. Frenkel (1978), The Social Organization of Strike (Oxford, Blackwell).

Bolton, S. (2004), 'A Simple Matter of Control? NHS Hospital Nurses and New Management', Journal of Management Studies, 41, 2, 2318-2333.

Bosley, S. and J. Dale (2008), 'Health Care Assistants in General Practice: Practical and Conceptual Issues of Skill-Mix Change', British Journal of General Practice, 58, 547, 118 124. 
CIPD (Chartered Institute of Personnel and Development) (2012), Annual Survey Report, 2012 (London, CIPD).

Daykin, N. and B. Clarke (2000), “'They'll Still Get Bodily Care”. Discourses of Care and Relationships Between Nurses and Health Care Assistants in the NHS', Sociology of Health and Illness, 22, 3, 349-363.

Department of Health (2000), The NHS Plan (London, The Stationary Office).

Ferlie, E., L. Fitzgerald, G. McGivern, S. Dopson and C. Bennett (2013), Making Wicked Problems Governable? The Case of Managed Networks in Health Care (Oxford, Oxford University Press).

Hancock, H. and S. Campbell (2006), 'Developing the Role of the Health Care Assistant', Nursing Standard, 20, 49, 35-41.

Hartley, J. and C. Skelcher (2008), 'The Agenda for Public Services Improvement', in J. Hartley, C. Donaldson, C. Skelcher and M. Wallace (eds), Managing To Improve Services (Cambridge, Cambridge University Press) pp. 2-24.

HSJ (Health Service Journal) (2013), 'Dr. Foster Identifies 13 Trusts With High Mortality Rates', Health Service Journal, 6 December, pp. 2-3.

Hyde, P., A. McBride, R. Young and K. Walshe (2005), 'Role Re-design: New Ways of Working in the NHS', Personnel Review, 34, 6, 697-712.

Keeney, S., F. Hasson, H. McKenna and P. Gillen (2005), 'Nurses' Midwives' and Patients' Perceptions of Trained Health Care Assistants', Issues and Innovations in Nursing Practice, 50, 4, 345-355.

Kessler, I., S. Bach and P. Heron (2013), 'Indeterminacy and the Regulation of Task Allocation: The Shape of Support Roles in Healthcare', British Journal of Industrial Relations, 51, 2, 310-332.

Long, C., S. Harding, K. Payne and L. Collins (2014), 'Nursing and Health-care Assistant Experience of Supervision in a Medium Secure Psychiatric Service for Women: Implications for Service Development', Journal of Psychiatric and Mental Health Nursing, 21, 2, 154-162.

Nancarrow, S. and A. Borthwick (2005), 'Dynamic Professional Boundaries in the HealthCare Workforce', Sociology of Health and Illness, 27, 7, 897-919.

RCN (Royal College of Nursing) (2012) 'NHS Agenda for Change Pay Scales-2012-2013'. Accessed 5 December 2013 from http://www.rcn.org.uk/publications

Saks, M. and J. Allsop (2007), 'Social Policy, Professional Regulation and Health Support in the United Kingdom', Social Policy \& Society, 6, 2, 165-177.

Spilsbury, K. and J. Meyer (2004), 'Use Misuse and Non-use of Health Care Assistants: Understanding the Work of Health Care Assistants in a Hospital Setting', Journal of Nursing Management, 12, 6, 411-418.

Thornley, C. (2000), 'A Question of Competence? Re-evaluating the Roles of the Nursing Auxiliary and Health Care Assistants in the NHS', Journal of Clinical Nursing, 9, 3, 451-458.

Thornley, C. (2007), 'Efficiency and Equity Considerations in the Employment of Health Care Assistants and Support Workers', Social Policy and Society, 7, 2, 147-158.

Wakefield, A. (2002), 'Tensions Experienced by Student Nurses in a Changed NHS Culture', Nurse Education Today, 20, 7, 571-578.

Wise, S. (2007), 'Wanted: The Next Generation of Nurse and Midwifery Managers', International Journal of Public Sector Management, 20, 6, 6473-6483. 